\title{
Social capital as an explanatory variable: Explaining the differential socio-economic performance in two mountainous rural areas in Greece
}

\author{
P. Karametou \& C. D. Apostolopoulos \\ Department of Home Economics and Ecology, \\ Harokopio University Athens, Greece
}

\begin{abstract}
The current transition of mountain environments with respect to environmental change, demographic, socio-economic and political transformations make them particularly sensitive or vulnerable to climatic, economic or other drastic changes. Nevertheless, all these areas do not present the same socio-economic performance and are not equally vulnerable to this transition process. Many works in rural development have emphasised the key role of social capital in order to explain the differential economic performance, social development and vulnerability between areas in different territorial levels. The purpose of this study is to analyse the degree to which the presence of social capital can affect the developmental processes and the potential of the local economies and interpret the differential economic performance in Greek rural areas. More specifically, two mountainous areas will be selected: the mountainous area of Pelion (Region of Thessaly, Prefecture of Magnesia) and the mountainous area of Zagori (Region of Epirus, Prefecture of Ioannina). So, what is most important in this study is to investigate social capital not only as a dependent variable but also as an explanatory variable that can contribute to the understanding of the specific socio-economic outcome of the aforementioned case study areas.

Keywords: Zagori, Pelion, Greek mountainous rural areas, social capital.
\end{abstract}




\section{Introduction}

The idea of social capital has enjoyed a remarkable rise to prominence in both the theoretical and applied social science literature over the last decade. However, this concept is used in different ways and with diverse meanings. At times it refers to the capacity for cooperation, for trust and civicness and therefore to a particular form of local culture [12]. Voyer and Franke [13] argue that social capital refers to the networks of social relations that may provide individuals and groups with access to resources and supports.

It is not so clear who used the term first, but an important early use came from Loury (1977) in her book "A Dynamic Theory of Racial Income Differences" [2]. However, the works of Bourdieu (1985), Coleman (1988), Putnam (1993a) and Fukuyama (1995; 1999;) were those that undoubtedly contributed to the widespread diffusion of the term of social capital in both academic and policy debates [4; 1,9].

Regarding the common elements and differences in their syllogism, we can say that Loury, Bourdieu and Coleman all argued that social capital is not embodied in any particular person, but rather in people social relationships. In parallel, they also supported that social capital was realized by individuals. On the contrary, Putnam [8] has argued that social capital is a source that individuals or groups of people possess or fail to possess. According to her opinion, "working together is easier in a community blessed with a substantial stock of social capital". So it's clear that for Putnam [8] "communities, not people possess 'stocks' of social capital and so social capital can be simultaneously a 'private good' and a 'public good"'.

What is most important is to understand that all the aforementioned opinions have strong and week points and they can, therefore, offer an integrated framework in the research of social capital. Everyone who studies social capital should not disapprove any of these thoughts but they had better try to familiarize themselves with the basic ideas behind them, to adapt and exploit them. For example, DeFilippis [2] argues that if we were going to use the notion of social capital in community development it would be more effective to do so in the way Loury or Bourdieu had conceived of it.

At present, the relationship between social capital and socio-economic development constitutes a controversial relation with both positive and negative interconnections and interactions. Putnam [9] argues that the social capital and the civil society promote economic growth. Furthermore, according to Knack and Keefer [6], much of the economic backwardness in the world can be explained by the lack of mutual confidence. Moreover, they argue that low levels of trust in a society could probably discourage its process of innovation. What is very interesting is that societies that are characterized by high levels of trust are also less dependent on formal institutions to enforce agreements. In additional, government officials in societies with higher trust may be perceived as more trustworthy, and their policy pronouncements are more credible [6]. 
On the other hand, according to Trigilia [12], social capital does not have only positive impacts but it can also create obstacles to local development. Therefore, it's important to study on what conditions social capital can favour local socio-economic development.

The main research question addressed in the present study is: "Why do certain mountainous rural areas in apparently similar economic, social and environmental circumstances have a different socio-economic performance over a relatively long period of time?" The basic hypothesis of this study is that the differential socio-economic performance is explained by the presence of different (high or low) levels of social capital and the way this operates in specific national, regional and local contexts. The main aim of this study is to measure the available stock of individual and collective social capital in the aforementioned case study areas, in order to reveal and interpret the relationship between their level of socioeconomic development and their available stock of social capital. What is important is to first construct a methodological instrument such as an integrated questionnaire suitable for the measurement of social capital in Greece and especially in mountainous rural areas. Finally, we have to understand how important it is to investigate social capital not only as a dependent variable, but also as an explanatory variable that can contribute to the understanding of a specific socio economic outcome.

\section{Methodology and research tasks}

The study of the aforementioned areas consisted of a historical analysis of the development of the area; interviews with key informants, such as officers of local authorities, organisms of local self-government, municipalities, local developmental agencies, local associations and voluntary organizations. The interviews involved the administration of a pre-coded questionnaire with a limited number of open-ended questions; analyses of secondary information relating to health, education, crime, employment, housing and deprivation. More specifically, the secondary information needed for a local economic assessment is the following: (a) Demographic information: population, education, age, (b) Economic and social information: employment, training, (c) Investments in enabling environment: laws, frameworks, enforcement, (d) Hard and soft infrastructure: transport, transportation links.

In order to measure social capital, a household survey will be used through a local based integrated questionnaire. The household survey will be carried out throughout the mountainous area of Pelion and Zagori and, as it is expected, this survey will provide the main empirical basis for this study. The questionnaire will be divided into nine different parts that they will provide information about the characteristics of the residents questioned in each of the study areas and robust evidence about the household members' participation in various types of social organizations and informal networks, and the range of contributions that one gives and receives from them. Furthermore, it will provide information about the citizen's trust towards neighbors and how these perceptions have changed over time, about the citizens' collective action and cooperation, their access to 
information and communications infrastructure. It will also provide information about the nature and the range of differences and mechanisms which threat the social cohesion and exclude some population groups from key public services. At the same time, there will be some suggestions about the individuals' empowerment and political action and the dynamics of social innovation in the case study areas.

In the following section, the results of the analysis of specific primary information regarding the case study areas will be presented.

\subsection{Zagori and Pelion: a study in contrast}

The mountainous regions in Greece cover a large part of the country, are of major environmental importance and present the lowest population density together with the highest density of villages per $100 \mathrm{~km}^{2}$. From a developmental point of view and due to their geomorphological characteristics and sensitive ecosystems, the mountainous regions also present intrinsic disadvantages related to the modernization of their traditionally extensive economic production basis or the creation of modern competitive production activities. These disadvantages are also inextricably related to the lack of adequate infrastructure and services. The most obvious outcome of these developmental shortages is the rapid rural depopulation process in these areas resulting in their economic, social and environmental degradation. Nevertheless, some mountainous areas such as Mt. Pelion, Mt. Parnassus and Metsovo have managed to take advantage of their local natural and cultural resources and thus have set the foundations for the development of local tourism and other sectors [10].

In this study, we investigate the extent of social capital in two different Greek mountainous areas, as measured by the locally based questionnaire, which covers all the main dimensions of social capital that have been identified from previous studies. For more details you can see studies such as those of Narayan and Pritchett, 1999; Grootaert, 2001; Grootaert and van Bastalaer, 2002; Narayan and Cassidy, 2001; World Bank, 2003, Ibanez, Lindert, and Woolock, 2002 [5]. Finally, we question the assumption that, by increasing social capital, social well-being and economic development can be improved.

At this point, however, it would be useful to describe those regional characteristics that determined the inclusion of the two specific study case areas in our study. More specifically, two mountainous areas were selected: the mountainous area of Pelion (Region of Thessaly, Prefecture of Magnesia) and the mountainous area of Zagori (Region of Epirus, Prefecture of Ioannina). Both of these areas exemplify the key 'victim' areas of the recent urban development trends in Greece and share many common characteristics with respect to their physical, geomorphological and historical conditions, their architectural style etc. However, these areas present different socio-economic developmental processes.

Regarding the first case study area, it belongs to this kind of areas which have enough resident population and economic sustainability, which is based on stock farming, forestry, traditional industry, tourist and vocational activities. Furthermore, the village complex of Pelion belongs to the Prefecture of 
Magnesia, one of the most dynamic and independent of agricultural activities, Greek prefectures, in which population constantly rises.

The second case study area includes the village complex of Zagori. This area tends to become highly isolated, since many inhabitants have already moved to urban areas and also faces a lot of environmental problems such as soil erosion, and insufficient preservation of the residential works and monuments. Moreover, this area belongs to the region of Epirus and to the prefecture of Ioannina. Epirus ranks last amongst the 13 Greek regions with regard to per capita GNP (approx. $70 \%$ of the national average). The prefecture of Ioannina has a decreasing income which is not based on the agricultural sector and there is also a gradual loss of its mountain population. Zagori is the most mountainous and most isolated area in the region.

Consequently, the context of this case study provides us with the opportunity to investigate social capital in two different socioeconomic areas that make up a representative sample of the Greek mountainous rural areas.

\subsection{Criteria for the selection of Regions and study areas}

As mentioned before, the basic hypothesis of this study is that the differential socioeconomic performance among mountainous rural areas is explained by the differential management of the available stock of social capital and the way this operates in specific national, regional and local contexts. According to Maloney et al [7], since social capital is context-specific, its existence can only be analyzed by taking into consideration some factors which are sensitive to the different locations in which the social capital is created or inhibited. This study in two different Greek mountainous areas allows us not only to analyze social capital in a specific local context, but also to look at its differences between two areas, which, although they are seemingly similar, they nevertheless have different social and economic characteristics. So what is more important in this study is to investigate and analyze whether and how the available stock of social capital relates to the social and economic differences between these areas.

To explain the differential socio-economic performance in the Greek mountainous areas, two different mountainous areas had to be selected with contrasting economic performance, that is one area with relatively "successful" performance and one with "less successful" performance. The selection of the regions and the study areas was based on common criteria. The Regions were selected on the basis of their GPD per head, policy status and degree of rurality, according to OECD criteria. On the other hand, the study areas were selected on the basis of their "contrasting economic performance, assessed mainly by employment changes, population changes (especially in-migration and outmigration) and changes in the net creation of enterprises. This methodology was used in many researches, in order to explain differential socio-economic performance. A representative example is the research work which was designed and developed by the Agricultural University of Athens within the European project DORA "Dynamics of Rural Areas" [3]. 


\subsection{First findings regarding the differential socio - economic performance of the study areas after the first assessment of the local economy, which was based on secondary data}

In the two Greek mountainous study areas, the differential economic performance was based upon the analysis of four interrelated indicators, i.e. the population evolution, the labour force evolution the employment trends and the GDP (in million euro) growth.

Firstly there will be a description of the differential socio-economic performance between the two different regions to which the case study areas belong. More specifically, Table 1 clearly shows that the Region of Thessaly, to which the mountainous area of Pelion belongs, has shown a much more rapid population increase that the region of Epirus, to which the mountainous area of Zagori belongs. Regarding the two study prefectures, Magnesia, to which the mountainous area of Pelion belongs, has shown a much more rapid population increase than the Prefecture of Ioannina, to which the mountainous area of Zagori belongs.

Table 1: The population change of the case study areas between 1991 and 2001.

\begin{tabular}{|l|c|c|}
\hline \multirow{2}{*}{} & \multicolumn{2}{|c|}{ Population } \\
\cline { 2 - 3 } & Year of 1991 & Year of 2001 \\
\hline Region of Thessaly & 734,846 & 753,888 \\
\hline Region of Epirus & 339,728 & 353,820 \\
\hline Prefecture of Magnesia & 198,493 & 207,973 \\
\hline Prefecture of Ioannina & 158,193 & 170,200 \\
\hline Greece & $10,260,900$ & 10,940 \\
\hline
\end{tabular}

Table 2 [14], presents the investigating climate in the Regions of Thessaly and Epirus. The first view is that the Region of Thessaly has an enormous growth in the number of the founded companies. In 2005, 116 companies were founded in Thessaly, in opposition with the Region of Epirus in which only 54 companies were established. The second and very important thing is the change of the invested capital. Compared with the region of Epirus, the region of Thessaly has had a much more positive change of $50.5 \%$ in the invested capital. On the other hand, the Region of Epirus presents an important decrease in the invested capital. Something that is very important and creates a big dissatisfaction for the Region of Epirus is the big reduction in the invested capital, especially in the domain of tourism (-74.0\%). Nevertheless, tourism could possibly be the main pillar of the future developmental process in this region.

In addition, Table 3 [14] presents the investigating climate in the Prefectures of Magnesia and Ioannina. The first important thing is the big reduction of the invested capital in the Prefecture of Ioannina, mainly in the tourist sector but also in the commercial and services sectors. On the other hand, tourism in Magnesia is well developed and highly contributes to the total invested capital in this Prefecture. 
Table 2: $\quad$ The Region's changing investigating climate (2005).

\begin{tabular}{|l|c|c|c|c|c|c|}
\hline \multirow{3}{*}{ Branch } & \multicolumn{3}{|c|}{ Region of Thessaly } & \multicolumn{3}{c|}{ Region of Epirus } \\
\cline { 2 - 8 } & $\begin{array}{c}\text { Number of } \\
\text { companies } \\
\text { founded }\end{array}$ & Change \% & $\begin{array}{c}\text { Change } \\
\text { of } \\
\text { Invested } \\
\text { Capital } \\
\%\end{array}$ & $\begin{array}{c}\text { Number of } \\
\text { companies } \\
\text { founded } \\
\%\end{array}$ & $\begin{array}{c}\text { Change } \\
\text { Change of } \\
\text { Invested } \\
\text { Capital } \\
\%\end{array}$ \\
\hline Industrial & 27 & $22.7 \%$ & $146.9 \%$ & 13 & $-7.1 \%$ & $1.0 \%$ \\
\hline Commercial & 34 & $-8.1 \%$ & $-36.5 \%$ & 14 & $133.3 \%$ & $58.7 \%$ \\
\hline Services & 42 & $-14.3 \%$ & $51.3 \%$ & 21 & $-8.7 \%$ & $2.1 \%$ \\
\hline Tourism & 13 & 160.0 & $132.9 \%$ & 6 & $50.0 \%$ & $-74.0 \%$ \\
\hline TOTAL & 116 & $2.7 \%$ & $50.5 \%$ & 54 & $14.9 \%$ & $-11.3 \%$ \\
\hline
\end{tabular}

Table 3: $\quad$ The Prefecture's changing investigating climate (2005).

\begin{tabular}{|l|c|c|c|c|c|c|}
\hline \multirow{3}{*}{ Branch } & \multicolumn{3}{|c|}{ Prefecture of Magnesia } & \multicolumn{3}{c|}{ Region of Ioannina } \\
\cline { 2 - 7 } & $\begin{array}{c}\text { Number of } \\
\text { companies } \\
\text { founded }\end{array}$ & $\begin{array}{c}\text { Change } \\
\%\end{array}$ & $\begin{array}{c}\text { Change } \\
\text { of } \\
\text { Invested } \\
\text { Capital } \\
\%\end{array}$ & $\begin{array}{c}\text { Number of } \\
\text { companies } \\
\text { founded }\end{array}$ & $\begin{array}{c}\text { Change } \\
\%\end{array}$ & $\begin{array}{c}\text { Change of } \\
\text { Invested } \\
\text { Capital } \\
\%\end{array}$ \\
\hline Industrial & 2 & $-50.0 \%$ & $98.3 \%$ & 9 & $-18.2 \%$ & $13.6 \%$ \\
\hline Commercial & 6 & $-40.0 \%$ & -44.05 & 5 & $150.0 \%$ & $-48.4 \%$ \\
\hline Services & 11 & $-38.9 \%$ & $-18.8 \%$ & 14 & $-17.6 \%$ & $-4.7 \%$ \\
\hline Tourism & 7 & $75.0 \%$ & $33.4 \%$ & 5 & $66.7 \%$ & $-75.0 \%$ \\
\hline \multicolumn{7}{|l|}{} \\
\hline TOTAL & 26 & $-27.8 \%$ & $0.3 \%$ & 33 & $0.0 \%$ & $-24.8 \%$ \\
\hline
\end{tabular}

\section{Conclusions}

The study examined the existence of differential economic performance in two Greek rural areas. The first results of the study concluded that these areas exhibit different economic records over a relatively long period of time, despite the fact that they have quite similar geographical and policy contexts. More specifically, the first case study area, which belongs to the Region of Thessaly, is an area with a relatively "successful" performance and the other area which belongs to the Region of Thessaly is an area with "less successful" economic performance. Nevertheless, a more systematic and detailed presentation of the parameters of their socioeconomic performance is needed, which will be the subject of another paper.

Regarding the next step of this study, this will be the measurement of the available stock of social capital in the aforementioned case study areas. The object of this analysis will not just be an individual, group or community. Rather, the relations among all these units will be analyzed. The value of different forms of social capital is context dependent. Social capital does not function in a vacuum. It is affected by complements, or reinforces the role of other resources 
that have relevance to a particular challenge or issue. It is therefore necessary to consider the value of different types of social capital in the context of the specific Greek mountainous rural areas.

\section{References}

[1] Coleman, J., Social Capital in the creation of human capital, American Journal of Sociology, 94 (September), pp. 95-120, 1988.

[2] DeFilippis, J., The Myth of Social Capital in Community Development. Housing Policy Debate, 12 (4), pp. 781-806, 2001.

[3] Efstratoglou, S., Papadopoulos, A., Efstratoglou, A. \& Kouroussi, E., National Report-Greece, FAIR6-CT98-4162 Research Project DORADUNAMICS OF RURAL AREAS, Agricultural University of Athens, 2001.

[4] Forrest, R. \& Kearns, A., Social Cohesion, Social Capital and the Neighbourhood. Urban Studies, 38 (12), pp. 2125-2143, 2001.

[5] Grootaert, C., Narayan, D., Nyham, J. \& Woolock, M., Measuring Social Capital: An Integrated Questionnaire. World Bank Working Paper, No. 18, THE WORLD BANK Washington, D.C., 2004.

[6] Knack, S. \& Keefer, P., Does Social Capital Have an Economic Payoff? A Cross-Country Investigation. The Quarterly Journal of Economics, 4 (November), pp.1251-1288, 1997.

[7] Middleton, A., Murie, A. \& Groves, R., Social Capital and Neighborhoods that work, Urban Studies, 42 (10), pp. 1711-1738, 2005.

[8] Putnam, R.D., Bowling Alone: The collapse and Revival of American Community, New York: Simon and Schuster, 2000.

[9] Putnam, R.D., Making Democracy Work: Civic Traditions in Modern Italy. Princeton, NJ: Princeton University Press, 1993.

[10] Soutsas, K., Tsantopoulos, G., Arabatzis, G., \& Christopoulou, O., Tourist Development of Mountainous Regions: the case of Metsovo. Discussion Paper Series, 11 (7), pp. 111-128, Department of Planning and Regional Development, School of Engineering, University of Thessaly, 2005.

[11] Statistical Bureau, Greece, 1991 \& 2001.

[12] Trigilia, C., Social Capital and Local Development. European Journal of Social Theory, 4 (4), pp. 427-442, 2001.

[13] Voyer, J.P. \& Franke, S., Social Capital as a Public Policy Tool: Conclusion from the PRI Project, Presentation in the Social Capital and Public Policy Seminar, University of Toronto, 2006.

[14] ICAP, 2005. 